\title{
Monitoring dissolved gases in thermal water to assess the potential relation between fluid evolution and seismicity
}

\author{
SÉBASTIEN GIROUD ${ }^{1}$, DR. YAMA TOMONAGA ${ }^{2}$, \\ MATTHIAS BRENNWALD ${ }^{1}$ AND ROLF KIPFER $^{3}$ \\ ${ }^{1}$ Swiss Federal Institute of Aquatic Science and Technology \\ ${ }^{2}$ Eawag, Swiss Federal Institute of Aquatic Science and \\ Presenting Author: sebastien.giroud@eawag.ch
} (Eawag)

Technology

${ }^{3}$ ETH Zurich

The correlation between seismic activity and changes of dissolved gas concentrations in deep groundwater is often and controversially discussed in the literature. There are numerous examples which yield evidence that seismic activity might lead to changes in fluid geochemistry - however, systematic non-sitespecific studies are hardly available and achieved results are not conclusive. This controversial situation is owed to the fact that most of these claims are based on a single seismic event whereas long-term observational data on fluid emanation in response to seismicity are notoriously scarce.

To gain adequately long time-series of geochemical data, we recently installed a portable gas equilibrium membrane-inlet mass spectrometer (miniRUEDI, Gasometrix GmbH [1]) at the prominent hydrothermal spring in Lavey-les-Bains (Switzerland) - discharging in one of the most seismically active regions in Switzerland. Water with a temperature of $\sim 67{ }^{\circ} \mathrm{C}$ is abstracted from a depth of $600 \mathrm{~m}$ and enters at the well head the miniRUEDI setup at a temperature $\sim 62^{\circ} \mathrm{C}$.

In this contribution, we report the first results of our attempt to record and analyse the evolution of $\mathrm{He}, \mathrm{Ar}, \mathrm{Kr}, \mathrm{N}_{2}, \mathrm{O}_{2}, \mathrm{CO}_{2}, \mathrm{CH}_{4}$ and $\mathrm{H}_{2}$ dissolved in the well water over a time span of several months. We will further critically assess if the measured gas concentrations somehow respond to (micro) seismic activity in the investigated region.

[1] Brennwald., Schmidt, Oser \& Kipfer (2016), ES\&T 50, 13455-13463. 